\title{
Reducing the Worldwide Burden of Cancer
}

\author{
Maurie Markman \\ University of Texas M.D. Anderson Cancer Center, Houston, Tex., USA
}

There is an increasing recognition within the oncology community of the immense burden associated with cancer among citizens of developing world countries. Consider, for example, the fact that of the approximately 500,000 women who develop cervix cancer worldwide each year, resulting in 250,000 deaths, $80 \%$ of all such cases will occur in the developing world [1].

The impact of the socio-economic status of these nations, and possibly unique cultural perspectives, will strongly influence how malignant conditions will be approached. Issues of the cost of anti-neoplastic drugs, the availability of radiation and hospital facilities, and the infrastructure for the delivery of screening, cancer prevention, and educational activities may result in substantially different concerns among clinicians and local oncology leaders compared to what is discussed and debated in the academic communities in the developed world.

Of great importance to the future improvement of the care of cancer patients worldwide is the truly impressive number of ongoing efforts being undertaken by individuals, organizations, and institutions to enhance the quantity and quality of oncology-related information and treatment being delivered in multiple settings. These initiatives are often entirely locally based, but may also represent the meaningful collaborative interactions between investigators and clinicians in both the developed and developing world. Further, many of these programs, large and small, have the realistic potential to favorably impact the outcome of individuals in a wide variety of clinical settings, and to substantially reduce the burden of cancer within a particular society (e.g., smoking cessation strategies; cervical or breast cancer screening).

Unfortunately, attempts to report the experiences of academic or community-based groups to build effective infrastructure under far less than optimal circumstances may not fair well in the peer-review process of medical or oncology journals, since the focus of such manuscripts will often be on descriptions and outcomes of the development of unique processes, rather than on results of scientific investigations.

This state of affairs is particularly problematic as many of these reports represent the culmination of major innovative efforts to both understand and overcome complex financial, political, and cultural barriers to the successful implementation of an effective cancer program. Whether these initiatives have involved 200 individuals in an extremely isolated rural village, or 200,000 people who have never participated in any form of cancer screening, the 'lessons learned' can be quite useful to others considering similar activities designed to improve outcomes in settings where resources and pre-existing relevant knowledge are distressingly limited.

It is the intent of Oncology to attempt to at least partially fill this serious void by providing a forum for the publication of high quality descriptions of a variety of regional, national or international efforts that focus on the unique aspects of the epidemiology of cancer, and the delivery of educational messages, preventive services, and oncology-related care within the developing world. To accomplish this goal, a new section of the journal entitled 'Reducing the Worldwide Burden of Cancer' will be initiated over the next several months, and we greatly look forward to receiving manuscripts for consideration for publication in this important initiative of Karger publishers.

\footnotetext{
Reference $\quad 1$ Wilson CM, Tobin S, Young RC: The exploding worldwide cancer burden: the impact of cancer on women. Int J Gynecol Cancer 2004;14:1-11.
}

\section{KARGER}

Fax +4161306 1234 E-Mail karger@karger.ch www.karger.com

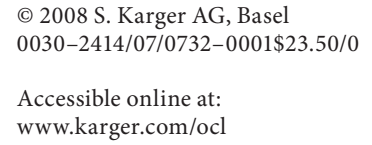

Dr. Maurie Markman

University of Texas M.D. Anderson Cancer Center

Unit 121, 1515 Holcombe Boulevard

Houston TX 77030 (USA)

Tel. +1 713745 7140, Fax +1 713563 9586, E-Mail mmarkman@mdanderson.org 